\title{
Gestión del agua subterránea en los acuíferos de la cuenca del río Ayuquila-Armería en Jalisco y Colima, México
}

\author{
Groundwater Management in the Aquifers of the \\ Ayuquila-Armería River Basin in Jalisco and Colima, Mexico
}

\author{
Rodrigo Alejandro Hernández Juárez* (D) http://orcid.org/0000-0001-6310-0269 \\ Luis Manuel Martínez Rivera** (iD) http://orcid.org/0000-0002-7050-9385 \\ Liliana Andrea Peñuela-Arévalo *** (i) http://orcid.org/0000-0003-2617-786X \\ Samuel Rivera-Reyes ${ }^{* * * *}$ (iD) http://orcid.org/0000-0003-3133-4727
}

\section{Resumen}

El objetivo de este artículo es analizar el papel de las concesiones de agua subterránea inscritas en el Registro Público de Derechos de Agua, como instrumento de planeación para el agua subterránea en la cuenca del río Ayuquila-Armería. Se utilizó una base de datos de dicho instrumento, con los registros de I994 a 20I5, para examinar el uso y el volumen de agua consumido en ese lapso en las concesiones otorgadas. A partir de 2009 hubo un incremento en estas variables y una disminución acelerada de la disponibilidad de agua en los acuíferos, por lo que algunos se consideraron "sobreexplotados". Se concluye que la delimitación administrativa de los acuíferos no contribuye a entender la dinámica geohidrológica, y que dicho instrumento no está funcionando para la planeación y el control, por lo que es necesario revisar la gestión actual del agua subterránea, y promover un cambio hacia una visión integral de ella, de acuerdo con la teoría de los sistemas de flujo.

Palabras clave: agua subterránea; acuíferos; Registro Público de Derechos de Agua; gestión de cuencas hidrográficas; concesiones.

\section{Abstract}

The objective of this article is to analyze the role of groundwater concessions registered in the Public Registry of Water Rights, as a planning instrument for groundwater in the Ayuquila-Armería river basin. A database of this instrument was used, with records from 1994 to 2015 , in order to examine the use and volume of water consumed in that period in the concessions granted. As of 2009 there was an increase in these variables and an accelerated decrease in the availability of water in the aquifers, so some were considered "overexploited". It follows that the administrative delimitation of aquifers does not contribute to understand the geohydrological dynamics, and that this instrument is not working for planning and control, so it is necessary to review the current management of groundwater, and promote a change towards an integral view of it, according to the theory of flow systems.

Keywords: groundwater; aquifers; Public Registry of Water Rights; hydrographic basins management; concessions.

Cómo citar: Hernández Juárez, R.A., Martínez Rivera, L. M., Peñuela-Arévalo, L.A.,y Rivera-Reyes, S. (20I9). Gestión del agua subterránea en los acuíferos de la cuenca del río Ayuquila-Armería en Jalisco y Colima, México. región y sociedad, 3 I, e l 093. doi: I 0.22 I 98/rys20 I 9/3 I/I 093

*Universidad de Guadalajara. Centro Universitario de la Costa Sur. Departamento de Ecología y Recursos Naturales. Avenida Independencia Nacional \#151, Centro, C. P. 48900. Autlán de Navarro, Jalisco, México. Correo electrónico: rambasu@yahoo.com

** Autor para correspondencia. Universidad de Guadalajara. Centro Universitario de la Costa Sur. Departamento de Ecología y Recursos Naturales. Avenida Independencia Nacional \#151, Centro, C. P. 48900. Autlán de Navarro, Jalisco, México. Correo electrónico: Imartinez@cucsur.udg.mx

*** Instituto Tecnológico de Estudios Superiores de Occidente. Periférico Sur Manuel Gómez Morín \#8585, C. P. 45604, San Pedro Tlaquepaque, Jalisco, México. Correo electrónico: lilianapenuela@gmail.com

**** Utah State University. College of Natural Resources. 5230 Old Main Hill, Logan, Utah 84322-5230, Estados Unidos. Correo electrónico: samuel.rivera@aggiemail.usu.edu

Recibido: 9 de julio de 2018

Aceptado: 22 de enero de 2019

Liberado: 26 de junio de 2019

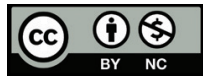




\section{Introducción}

El agua es indispensable para la supervivencia de los seres vivos y para el desarrollo y bienestar de las sociedades (Carabias, 2017, p. 22). En términos globales, el agua subterránea es el reservorio principal de agua dulce disponible físicamente (Hatch y Carrillo, 2017, p. 1). Según el estudio de Gleeson, Befus, Jasechko, Luijendijk y Cardenas, el volumen global de agua subterránea en los primeros dos kilómetros de la corteza terrestre es de 22.6 millones de $\mathrm{km}^{3}$, que varía entre 16 y $30 \mathrm{~km}^{3}$, según la incertidumbre del valor de porosidad utilizado; sin embargo, es finita la cantidad que se puede renovar en el periodo de una vida humana, de 25 a 100 años, lo que la convierte en un recurso limitado (2016, p. 6); cuya distribución es heterogénea y dependiente de la condiciones hidrogeológicas, topográficas y climáticas (Tóth, 2009, p. 93).

En el mundo, el agua subterránea provee $36 \%$ del abastecimiento de agua potable, $43 \%$ se destina a la agricultura de riego y 24 al uso industrial (Döll et al., 2012, p. 143). Sin olvidar su papel en el desarrollo de energías naturales (geotérmica, petróleo y gas) y el mantenimiento de ecosistemas acuáticos sanos (ríos, lagos y humedales), que dependen de su descarga (Foster y Cherlet, 2014, p. 5).

Hasta hace poco se tenía la idea falsa de que el agua es un recurso natural renovable ilimitado (Carabias, 2017, p. 21); y al incrementarse su uso han surgido retos nuevos en los aspectos socioeconómicos de su distribución, el uso eficiente y la sustentabilidad del recurso. De acuerdo con la United Nations Educational, Scientific and Cultural Organization (UNESCO, 2012, p. 85), la extracción de agua subterránea se ha triplicado en los últimos 50 años y continuará aumentando, lo que provocará disminución en su abastecimiento, contaminación y la degradación ambiental asociada; situaciones que se han vuelto comunes en todo el mundo (Organización de las Naciones Unidas para la Alimentación y la Agricultura, 2016, p. 10).

Según la UNESCO, cerca de $72 \%$ de la extracción de agua subterránea en todo el mundo se lleva a cabo en 10 países, y México es uno de los que más consumen (2012, p. 85), ya que de dicha fuente proviene $39.1 \%$ del volumen concesionado para usos consuntivos, y los consumidores principales son los sectores agrícola y público urbano (Comisión Nacional del Agua [CONAGUA], 2018, p. 77).

En México ha aumentado el número de acuíferos sobreexplotados; de los 653 establecidos por la CONAGUA, 32 estaban en dicha condición en 1975; 80, en 1985; 97, en el año 2000 y 106, en 2013 (Carrillo-Rivera et al., 2016, p. 7). Quizá lo más preocupante es que de esos acuíferos se extrae $56 \%$ del total del agua para los diferentes usos en el país (Hatch y Carrillo, 2017, p. 3). En Jalisco, en 2015, 25 de los 58 acuíferos existentes (43\%) estaban catalogados como sobreexplotados (CONAGUA, 2015).

La cuenca del río Ayuquila-Armería, en Jalisco, está conformada por siete acuíferos administrativos, en los cuales las concesiones y el volumen concesionado de agua subterránea se han incrementado de manera importante de 2008 a 2015. Según la CONAGUA, en abril de 2015 el acuífero Autlán era el único 
sobreexplotado, y para diciembre de ese mismo año, el Jiquilpan ya se consideraba en esta categoría. La situación de la gestión del agua subterránea en estos acuíferos pasó de ser favorable a desfavorable en un periodo de dos años.

En México, de acuerdo con el artículo 27 constitucional y el 18 de la Ley de Aguas Nacionales (LAN), es atribución del Poder Ejecutivo federal la gestión del agua subterránea, que ejerce a través de la CONAGUA, y cuya explotación, uso o aprovechamiento se realizará mediante una concesión o asignación, que quedará asentada en el Registro Público de Derechos de Agua (REPDA), como instrumento de apoyo para planear y programar su administración (CONAGUA, 2012, p. 11).

De conformidad con la información contenida en la base de datos del REPDA, aquí se busca analizar la gestión del agua subterránea según el sistema de concesiones en los acuíferos de la cuenca del río Ayuquila-Armería, mediante el número de concesiones, los volúmenes otorgados y su uso, de 1994 a 2015. Se revisan aspectos del método oficial para calcular la disponibilidad de agua subterránea y algunos de los principios normativos de la legislación actual, con el objetivo de identificar áreas de oportunidad para lograr una gestión integral y asegurar su permanencia en el largo plazo.

\section{Sistema de derechos de agua, el REPDA y el balance hídrico}

En el mundo existen varios modelos de asignación de derechos de agua, que se basan en principios diferentes y con regímenes de propiedad distintos para la explotación de las aguas subterráneas. Algunos ejemplos son las doctrinas de propiedad absoluta, uso razonable y derechos correlativos en Estados Unidos, el modelo de administración pública según un sistema de derechos de uso de agua utilizado en Colombia o los de distribución basados en el mercado, como en Chile (Méndez, 2008, pp. 160-162). Sin embargo, ninguno ha logrado una asignación completa, eficiente y equitativa del agua, debido a los problemas técnico-económicos y las condiciones de distribución y disponibilidad del recurso que enfrenta cada país.

El modelo administrativo mexicano se caracteriza por una autoridad administrativa estatal que es la propietaria de los derechos de agua, que asigna los permisos de consumo y determina la disponibilidad y las condiciones para éste, lo cual le otorga la responsabilidad de prever y planear el destino más apropiado para los usos del agua (Pineda-Pablos, Moreno-Vásquez, Salazar-Adams y Lutz-Ley, 2014, p. 193). De acuerdo con la LAN, el criterio principal para otorgar las concesiones es la condición de que exista una disponibilidad media anual del agua favorable en el lugar que se solicita (Diario Oficial de la Federación [DOF], 2016a, p. 64), la cual se determina por medio de un balance de agua, según la ecuación establecida en la Norma Oficial Mexicana NOM-011CNA-2015 (DOF, 2015b, p. 6). 
Disponibilidad media

anual de agua del subsuelo = recarga total $\quad$-descarga $\quad$-volumen anual de agua en un acuífero media anual natural subterránea concesionado comprometida e inscrito en el REPDA

Donde la disponibilidad de agua subterránea es el volumen medio anual que puede ser extraído de una unidad geohidrológica para usos diversos, adicional a la extracción ya concesionada y la descarga natural comprometida. La recarga total media anual se determina mediante un balance de agua, donde la entrada (recarga) a un sistema acuífero es igual al cambio en el almacenamiento, menos la sumas de salidas de descarga natural y artificial.

La descarga natural comprometida es la fracción de la descarga natural de un acuífero, comprometida como agua superficial destinada para varios usos o que se debe conservar para prevenir un daño ambiental a los ecosistemas o la migración de agua de mala calidad a un acuífero, y se determina por alguno de los métodos descritos en el apéndice " $B$ " de la norma (DOF, 2015b, p. 11).

En México, la administración del agua se ha entendido, históricamente, como una obra hidráulica basada en un enfoque constructivo, en oposición a una visión del agua como elemento natural en su dimensión de uso y conservación (Carrillo-Rivera et al., 2016, p. 2). Esto según un paradigma orientado a la gestión de la oferta, es decir, a incrementar los volúmenes extraídos o importados sin considerar la sostenibilidad de las fuentes, en donde el valle de México es quizá uno de los ejemplos más representativos (Ortega y Velasco, 2012, p. 15). El crecimiento continuo de la población, así como el incremento de las necesidades básicas para mantener las actividades económicas, como ocurre en el valle de México, han llevado a aumentar la extracción del agua subterránea a profundidades cada vez mayores, sin conocer su dinámica y su interacción con el entorno, con efectos negativos para los ecosistemas, abatimiento de los niveles freáticos o hundimiento del terreno (Peñuela, García y Carrillo, 2016, pp. 160-163). Dicho aumento también ha causado un cambio en las dinámicas de flujo, y ocasionado la descarga inducida de un sistema de flujo regional profundo con otra calidad que afecta la disponibilidad de agua (Huizar-Alvarez, Ouysse, Espinoza-Jaramillo, Carrillo-Rivera y Mendoza-Archundia, 2016, p. 15). Al igual que en la cuenca del Valle de México, la extracción intensiva en la región lagunera (Gutiérrez y Ortiz, 2017, p. 139), la cuenca Lerma-Chapala (Ortega-Guerrero 2009, p. 159) y la ciudad de San Luis Potosí (Hergt, Larragoitia, Benavides y Carrillo-Rivera, 2009, p. 51) ha producido la descarga inducida de agua subterránea rica en elementos nocivos para la salud humana, como fluoruro o arsénico. 


\section{Materiales y métodos}

Área de estudio

La cuenca del río Ayuquila-Armería se localiza en el occidente de México, y forma parte de la región hidrológica 16 Armería-Coahuayana, ubicada entre los $102^{\circ} 56^{\prime}$ y $104^{\circ} 35^{\prime}$ de longitud Oeste y los $18^{\circ} 40^{\prime}$ y $20^{\circ} 29^{\prime}$ de latitud Norte, cuenta con una superficie de $9731 \mathrm{~km}^{2}$, de los cuales $81 \%$ pertenece a Jalisco y 19 a Colima (DOF, 2016b, p. 3). Se encuentra dentro de una zona de transición de los reinos biogeográficos Neártico y Neotropical, lo cual le confiere características muy importantes en cuanto a la diversidad de flora y fauna (Jardel, 1992, p. 315).

El río Ayuquila-Armería es uno de los 15 más importantes de los 100 existentes en la vertiente del Pacífico, y está entre los 43 principales de México (Graf-Montero, Martínez-Rivera, Santana-Castellón e íñiguez-Dávalos, 2002). Este río, además de ser fuente de abastecimiento para las poblaciones aledañas, constituye un soporte para la biodiversidad, pues cuenta con 14 especies nativas de peces, dos de las cuales son endémicas (Martínez-Rivera, Graf-Montero, Santana-Castellón y García, 2005, p. 2). Dentro de la cuenca se han realizado obras de infraestructura hidráulica, las más importantes son las presas de Tacotán, Trigomil, Las Piedras y El Nogal, en Jalisco, y dos presas derivadoras para dotar de agua a los distritos de riego 094 El Grullo-Autlán, en Jalisco y el 053 Peñitas, en Colima.

En 2010, la población total de la cuenca era de 678670 habitantes; 222742 (33\%) residentes en Jalisco, y 455928 (67) en Colima (Instituto Nacional de Geografía y Estadística [INEGI], 2010). Los centros de población más importantes son Autlán, El Grullo, Ayutla, Techaluta, Tecolotlán, San Gabriel, Unión de Tula, Tenamaxtlán y Tapalpa, en Jalisco, y Colima (capital del estado), Coquimatlán, Armería y Villa de Álvarez, en Colima. Las actividades económicas principales de la cuenca son la agricultura, la ganadería, la minería, la explotación silvícola y forestal, el comercio, la pesca y los servicios (DOF, 2016b, p. 6).

La cuenca abarca parte o la totalidad de la superficie de los acuíferos administrativos Unión de Tula, Autlán, Tecolotlán, Tapalpa, Jiquilpan, Colima y Armería-Tecomán-Periquillos (ATP), delimitados por la CONAGUA (DOF, 2003, p. 53), que son de tipo libre, ubicados en zonas montañosas, mesetas y valles; el de ATP es el único costero (véanse tabla 1 y figura 1). Estos acuíferos cuentan con tres decretos de veda de control para las aguas del subsuelo, los establecidos en 1973 y 1984, para los municipios de la costa y el valle de Colima (CONAGUA, 2002, p. 6), y otro en 1987, para los de Jalisco (CONAGUA, 2008, p. 7).

\section{Análisis de la información}

La CONAGUA, por medio del Sistema de Solicitud de Información del Estado de Jalisco (INFOMEX Jalisco), a solicitud expresa, entregó la información del 
Figura 1. Ubicación de los acuíferos de la cuenca del río Ayuquila-Armería (a) y concesiones de agua subterránea por acuífero (b)

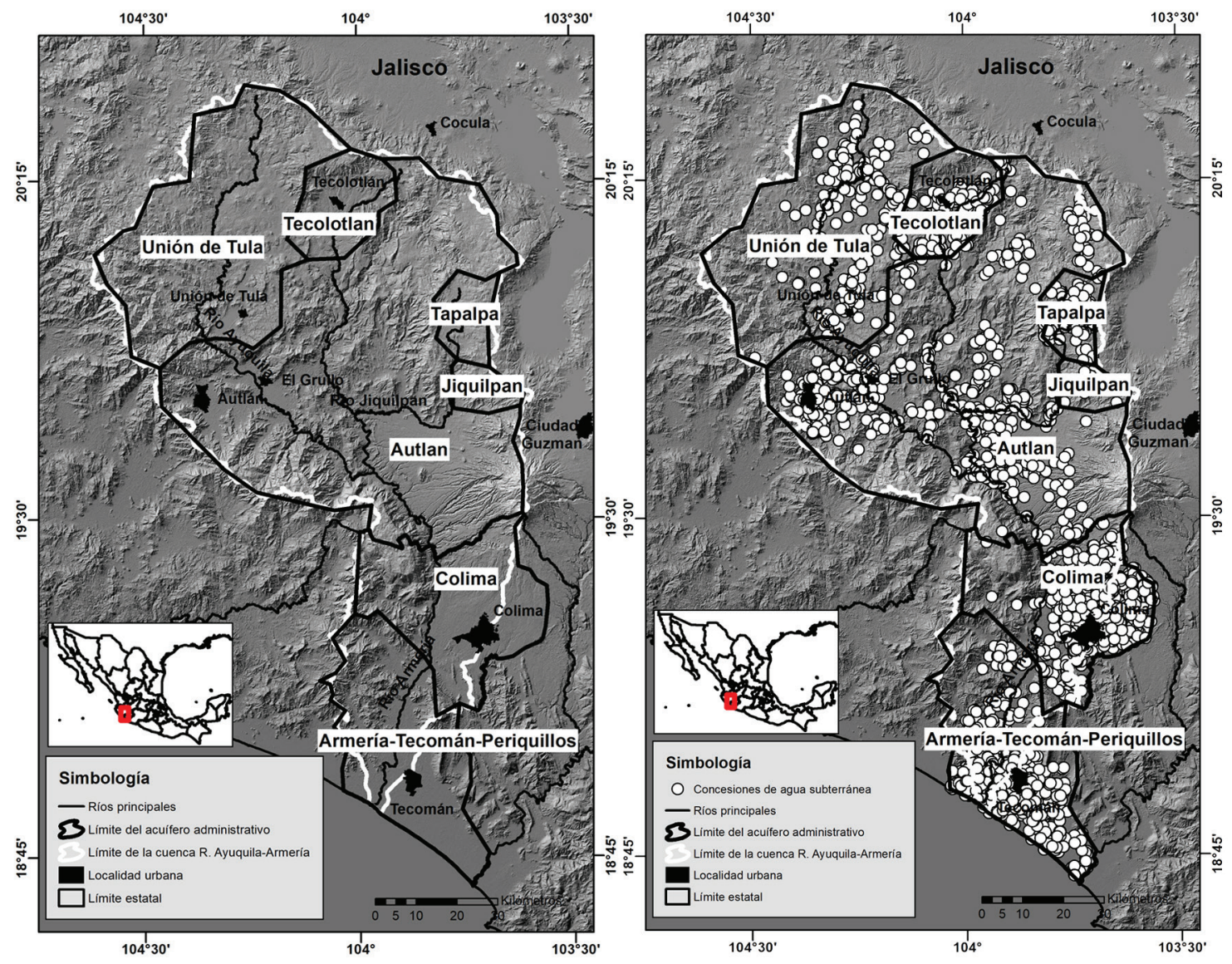

Fuente: elaboración propia, con información del REPDA (2015) e INEGI (2016).

REPDA en una base de datos que contenía 3172 registros de las concesiones de agua subterránea otorgadas, entre enero de 1994 y agosto de 2015, con las especificaciones siguientes: localización geográfica, código del título, volumen concesionado, cantidad de anexos, usos, plazo de la concesión, profundidad de la perforación, nombre del acuífero, gasto requerido, diámetro del pozo y si cuenta o no con medidor.

Estos registros se ingresaron al software ArcGis 10.2, del Environmental Systems Research Institute (ESRI), para su visualización, manipulación y análisis; después fueron reproyectados al sistema de referencia Universal Transversal Mecator UTM Zona $13 \mathrm{~N}$, con el datum WGS84, y se revisó su ubicación pues muchos se encontraron fuera de los límites de los acuíferos estatales o del territorio nacional e incluso en el mar. Luego se corrigieron con la información de localización, el programa Google Earth 6.1.5 y el marco geoestadístico del INEGI (2016). 
Se eliminaron de la base de datos todos los registros en los que no fue posible corregir su ubicación, y se realizó una selección espacial con los polígonos de los acuíferos, para elegir los que quedaron dentro de los acuíferos, y se obtuvieron 3122 registros (véase figura 1 ).

La cantidad de concesiones y el volumen concesionado se pueden utilizar como indicadores de la presión antropogénica, para cuantificar el uso e identificar las regiones con mayor presión sobre el agua subterránea (Díaz-Caravantes, Bravo-Peña, Alatorre-Cejudo y Sánchez-Flores 2013, p. 96). Con estas variables se generaron modelos espaciales de densidad, mediante la herramienta Densidad de Kernel en ArcGis. El cálculo de densidad se realizó con una resolución espacial de un $\mathrm{km}$ y radio de búsqueda de puntos vecinos de $15.6 \mathrm{~km}$. El cual se obtuvo con la herramienta de autocorrelación espacial incremental, que permite seleccionar la distancia donde los procesos espaciales que promueven el agrupamiento son más pronunciados (ESRI, 2014). Estos mapas se reclasificaron en tres clases: alta, media y baja, con el método de intervalos naturales, y se combinaron con el método de combinación lineal ponderada asignando la misma prioridad a cada variable para obtener un mapa de presión total (Díaz-Caravantes et al., 2013, p. 97).

\section{Resultados}

El acuífero Autlán es el más extenso, abarca $44 \%$ de la superficie total de los que conforman la cuenca, en tanto que Tapalpa y Jiquilpan solo cubren $2 \%$. El acuífero Colima cuenta con $34 \%$ de las concesiones totales, mientras que el ATP con $52 \%$ del volumen total concesionado (véanse tabla 1 y figura 2 ).

Tabla 1. Superficie, número de títulos, volumen concesionado y profundidad de perforación por acuífero

\begin{tabular}{|l|c|r|r|r|r|r|r|r|}
\hline Estado & Acuífero & $\begin{array}{c}\text { Superficie } \\
\left(\mathrm{km}^{2}\right)\end{array}$ & $\%$ & $\begin{array}{c}\text { Número } \\
\text { de } \\
\text { títulos }\end{array}$ & $\%$ & $\begin{array}{c}\text { Volumen } \\
\text { concesionado } \\
\left(\mathrm{Hm}^{3} / \mathrm{anno}\right)\end{array}$ & $\%$ & $\begin{array}{c}\text { Profundidad } \\
\text { de perforación } \\
\text { promedio (m) }\end{array}$ \\
\hline Colima & ATP & 1418 & 13 & 826 & 26 & 198.1 & 52 & 65 \\
\hline & Colima & 1305 & 12 & 1046 & 34 & 69.6 & 18 & 109 \\
\hline Jalisco & Autlán & 4698 & 44 & 747 & 24 & 78.0 & 20 & 64 \\
\hline & Jiquilpan & 163 & 2 & 36 & 1 & 5.9 & 2 & 135 \\
\hline & Tapalpa & 257 & 2 & 127 & 4 & 6.7 & 2 & 136 \\
\hline & Tecolotlán & 498 & 5 & 106 & 3 & 5.1 & 1 & 78 \\
\hline & $\begin{array}{c}\text { Unión de } \\
\text { Tula }\end{array}$ & 2296 & 22 & 234 & 7 & 18.5 & 5 & 108 \\
\hline Total & & 10635 & 100 & 3122 & 100 & 382.0 & 100 & 83 \\
\hline
\end{tabular}

Fuente: elaboración propia, con información del REPDA (2015). 
En conjunto, los acuíferos ATP, Colima y Autlán concentran $84 \%$ de las concesiones y 90 del volumen concesionado. En tanto que Jiquilpan, Tapalpa, Tecolotlán y Unión de Tula concentran $16 \%$ de las concesiones y 10 del volumen concesionado. Por otro lado, las mayores profundidades de perforación se ubican en los de Tapalpa, Jiquilpan, Colima y Unión de Tula (véase tabla 1).

\section{Disponibilidad media anual y volumen concesionado}

Cuando se analizó el valor de la disponibilidad publicada en el DOF, de acuerdo con la fecha de corte del REPDA, para el 20 abril de 2015, el acuífero Autlán era el único en déficit $\left(-1.8 \mathrm{Hm}^{3} / a n ̃ o\right)$; mientras que el resto aún mantenía una disponibilidad mayor ( $1 \mathrm{Hm}^{3} /$ año), excepto Jiquilpan; para el 31 de diciembre de ese mismo año ya se encontraba en déficit ( $-0.5 \mathrm{Hm}^{3} /$ año), y en el de Autlán se incrementó a $-6.0 \mathrm{Hm}^{3}$ /año (DOF, 2018, pp. 13-14) (véase tabla 2).

Tabla 2. Disponibilidad media anual de los acuíferos y de los parámetros que intervienen en su determinación (cifras en millones de metros cúbicos anuales)

\begin{tabular}{|c|c|c|c|c|c|c|c|}
\hline & \multicolumn{5}{|c|}{$\begin{array}{l}20 \text { de abril } \\
\text { de } 2015\end{array}$} & \multicolumn{2}{|c|}{$\begin{array}{c}31 \text { de diciembre } \\
\text { de } 2015\end{array}$} \\
\hline & $\begin{array}{c}\text { Recarga } \\
\text { media } \\
\text { anual }\end{array}$ & $\begin{array}{c}\text { Descarga } \\
\text { natural } \\
\text { compro- } \\
\text { metida }\end{array}$ & $\begin{array}{l}\text { Volumen de } \\
\text { extracción } \\
\text { de agua } \\
\text { subterránea } \\
\text { consignado } \\
\text { en estudios } \\
\text { técnicos }\end{array}$ & $\begin{array}{l}\text { Volumen } \\
\text { concesio- } \\
\text { nado de } \\
\text { agua } \\
\text { subterrá- } \\
\text { nea }\end{array}$ & $\begin{array}{c}\text { Disponi- } \\
\text { bilidad } \\
\text { media anual } \\
\text { de agua } \\
\text { subterrá- } \\
\text { nea }\end{array}$ & $\begin{array}{l}\text { Volumen } \\
\text { concesio- } \\
\text { nado de } \\
\text { agua } \\
\text { subterrá- } \\
\text { nea }\end{array}$ & $\begin{array}{l}\text { Disponi- } \\
\text { bilidad } \\
\text { media anual } \\
\text { de agua } \\
\text { subterr- } \\
\text { ánea }\end{array}$ \\
\hline \multicolumn{8}{|c|}{ Acuíferos en Colima } \\
\hline \multicolumn{8}{|l|}{ Colima } \\
\hline ATP & 230 & 20 & 152 & 197 & 13.4 & 206 & 3.0 \\
\hline Colima & 80 & 5 & 42 & 72 & 2.7 & 72 & 1.8 \\
\hline \multicolumn{8}{|c|}{ Acuíferos en Jalisco } \\
\hline Autlán & 76 & 0 & 19 & 78 & -1.8 & 79 & -6.0 \\
\hline Jiquilpan & 6 & 0 & 4 & 6 & 0.8 & 6 & -0.5 \\
\hline Tapalpa & 13 & 2 & 1 & 7 & 4.0 & 7 & 3.2 \\
\hline Tecolotlán & 21 & 4 & 1 & 7 & 10.1 & 7 & 8.6 \\
\hline $\begin{array}{l}\text { Unión } \\
\text { de Tula }\end{array}$ & 103 & 84 & 12 & 17 & 1.6 & 17 & 0.5 \\
\hline
\end{tabular}

Fuente: elaboración propia, con información del DOF (2015a, pp. 36-40; 2018, pp. 13-14). 
Al analizar el comportamiento de las variables que intervienen en el cálculo de la disponibilidad de 2003 a 2015 se observó una tendencia generalizada, donde el volumen de extracción concesionado se incrementó y disminuyó la disponibilidad, como en los acuíferos ATP, Autlán, Jiquilpan, Tapalpa, Tecolotlán y Unión de Tula (véase figura 2); en el ATP aumentó de manera continua desde 1994 hasta 2015, y llegó a $206 \mathrm{Hm}^{3}$ /año. Este volumen es entre seis y nueve veces mayor que el concesionado en los demás acuíferos, y solo $15 \%$ menor a su volumen de recarga (véanse tabla 2 y figura $2 a$ ). El acuífero Colima es el único que muestra una tendencia contrastante en el volumen concesionado y la disponibilidad, con incrementos y disminuciones ligeros en ambas variables (véanse tabla 2 y figura $2 b$ ).

En el acuífero Autlán hubo un crecimiento continuo en el volumen concesionado, con gran incremento entre 2009 y 2013, aunque a finales de 2015 fue de $79 \mathrm{Hm}^{3} /$ año, superando el volumen de recarga estimado $\left(76 \mathrm{Hm}^{3} /\right.$ año) por la CONAGUA (véanse tabla 2 y figura 2c y d). Situación que comparte Jiquilpan. Tecolotlán es el único que mantuvo una disponibilidad mayor al volumen concesionado (véanse tabla 2 y figura $2 f$ ).

Destaca otro aspecto importante, el comportamiento lineal de la recarga media anual y la descarga natural comprometida, que representa el aporte al flujo base de los ríos y arroyos para garantizar su conservación. Ya que el volumen de estas variables permaneció constante a lo largo del tiempo, o no estaba considerado en el cálculo de la disponibilidad, como en el caso de la descarga natural comprometida en Autlán y Jiquilpan (véase figura 2).

\section{Evolución de las concesiones en el tiempo}

Los registros y movimientos de concesiones han ido creciendo en la cuenca del río Ayuquila-Armería. En una primera etapa, de 1995 a 1999, la actividad se concentró por primera vez, en el registro de derechos de las extracciones existentes y, en una segunda, a partir del año 2000, la actividad registral disminuyó y aumentó el registro de movimiento y trasmisiones de derechos (Pineda et al., 2014, p. 204). En una tercera etapa, a partir de 2007-2008 hubo incrementos muy importantes en el número de concesiones y volúmenes concesionados (véase figura 3), los cuales están relacionados con los usos agrícola y público urbano.

\section{Uso de agua subterránea}

Los usos principales del agua subterránea en estos acuíferos son el agrícola, público urbano y múltiple, consumen 63,17 y $12 \%$ del volumen total concesionado, respectivamente. Los dos primeros representan $80 \%$ del total y más de $56 \%$ del total concesionado en cada acuífero. En conjunto, los usos acuícola, pecuario, industrial y de servicios constituyen $7 \%$ del volumen total concesionado. 
Figura 2. Comportamiento de las variables utilizadas en el cálculo de la disponibilidad, 2003-2015

\section{a) Acuífero Armería-Tecomán-Periquillos}

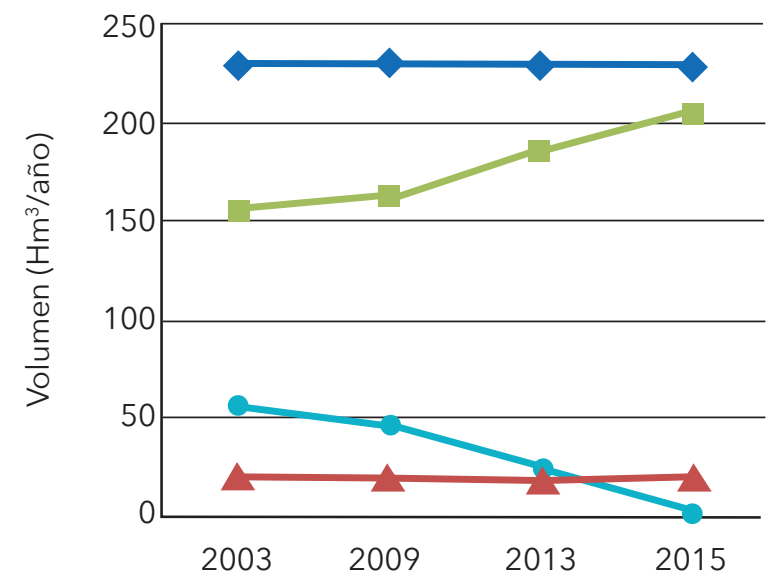

Recarga media anual

- Volumen concesionado

_- Disponibilidad media anual

Descarga natural comprometida

b) Acuífero Colima

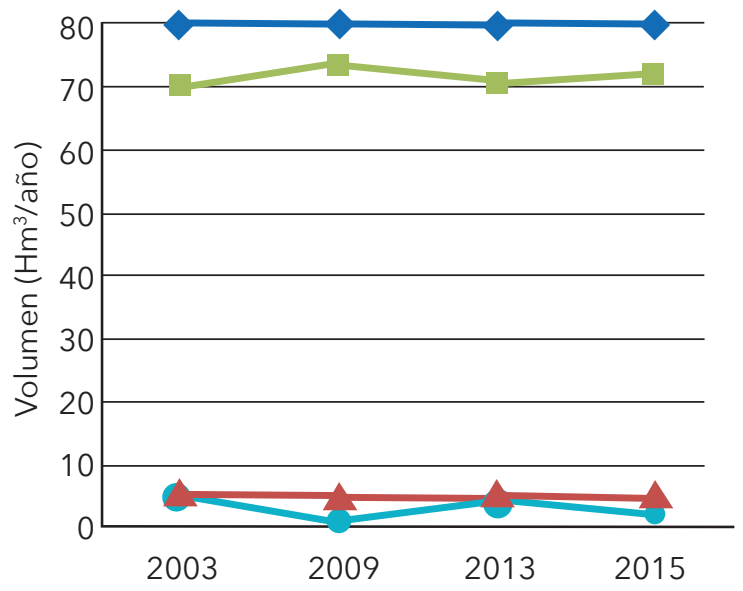

- Volumen concesionado

_ Disponibilidad media anual

Recarga media anual

Descarga natural

comprometida

c) Acuífero Autlán

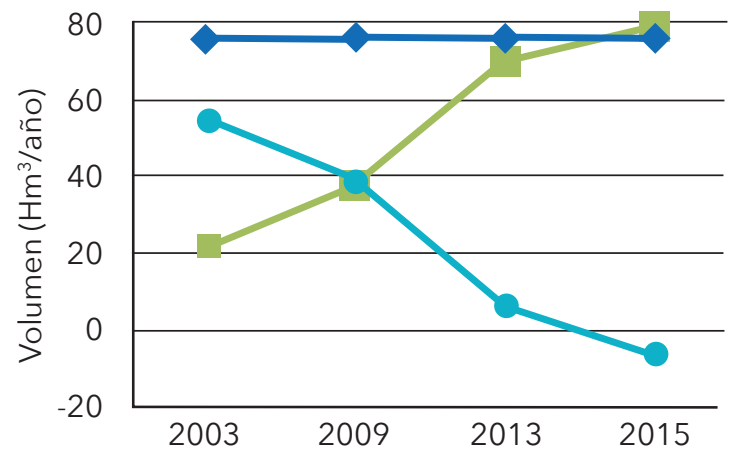

- Volumen concesionado

_- Disponibilidad media anual

Recarga media anual 


\section{d) Acuífero Jiquilpan}

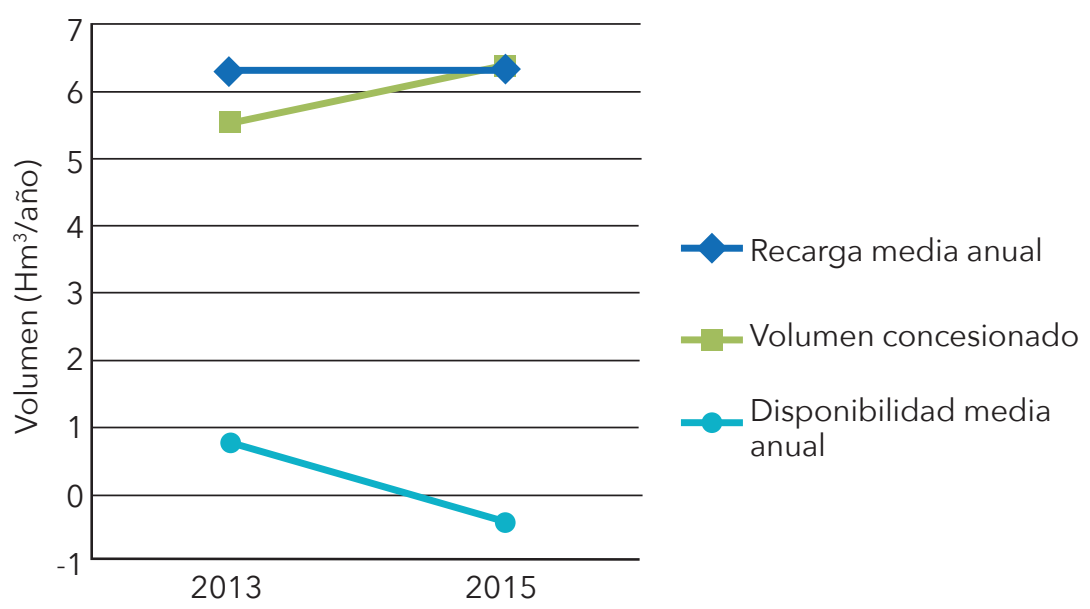

e) Acuífero Tapalpa

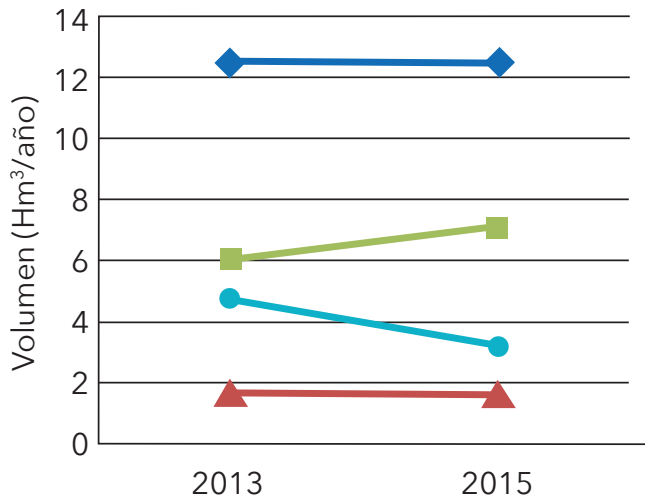

f) Acuífero Tecolotlán

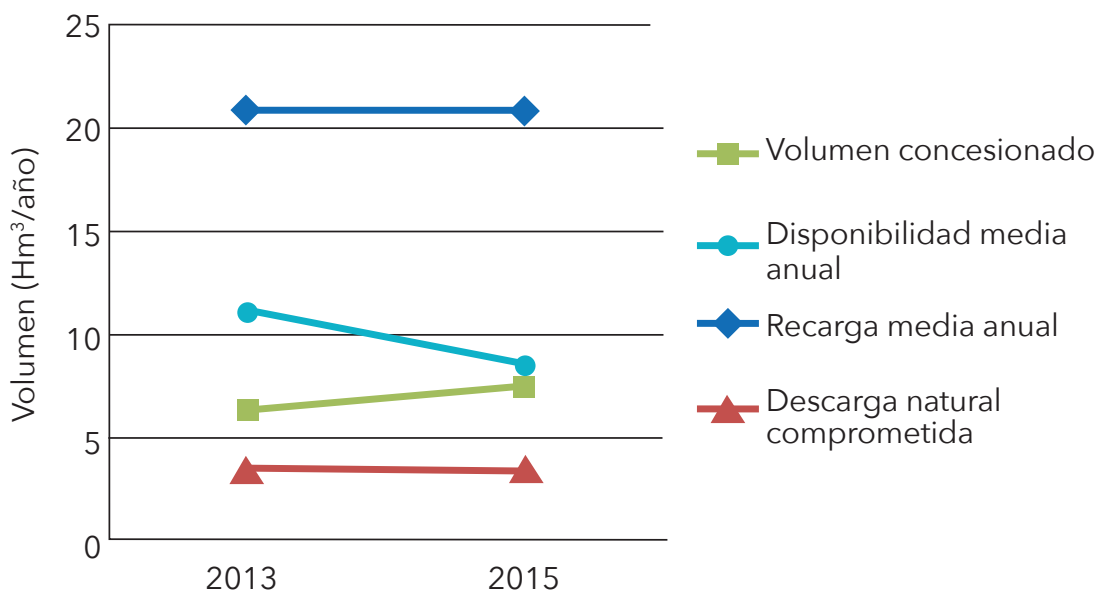


g) Acuífero Unión de Tula

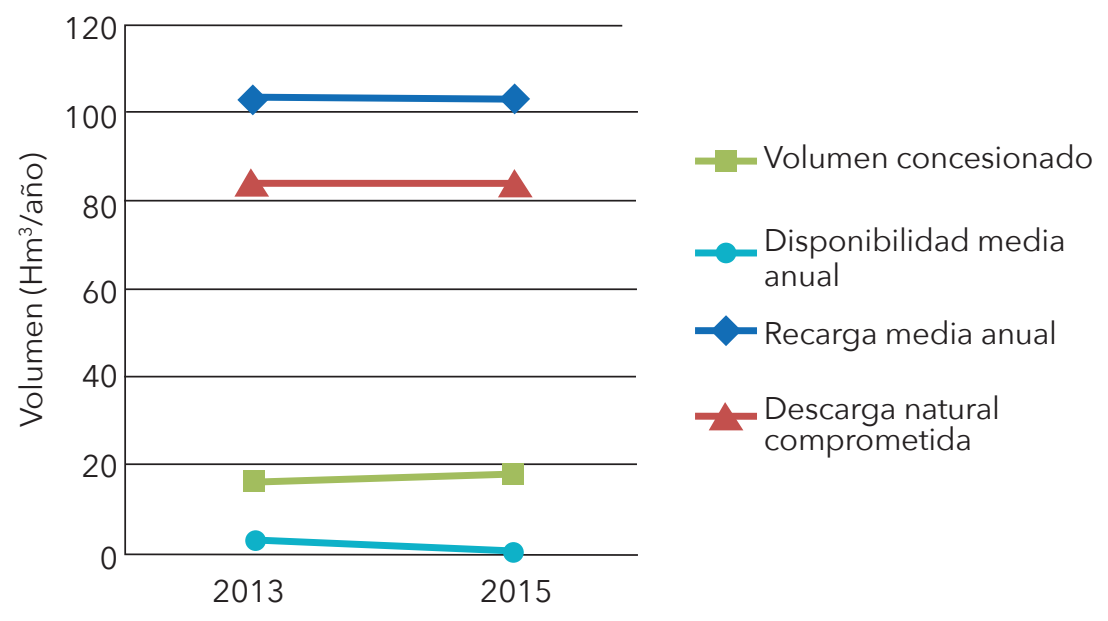

Fuente: elaboración propia, con información del DOF $(2003,2009,2013,2015,2018)$.

Los acuíferos ATP, Autlán, Jiquilpan, Tapalpa y Tecolotlán destinan a la agricultura más de $50 \%$ de su volumen concesionado, mientras que los ATP y Colima asignan 36 y $15 \%$ para uso público urbano (véanse figura $4 a$ y $4 b$ ).

Ambos usos han crecido de manera continua a lo largo del tiempo, con algunos aumentos importantes en el uso agrícola en los acuíferos Colima, ATP y Autlán, a partir del 2007 (véase figura 4a); sin embargo, el uso público urbano presenta incrementos abruptos en Colima, ATP y Autlán, a partir de 2008 (véase figura 4b). Éstos se relacionan con el otorgamiento de concesiones para los cultivos de maíz, pasto, caña de azúcar, agave, papa y avena, que son los más importantes (Rodríguez-Aguilar, 2017, p. 40); resalta el otorgamiento de concesiones con más de un millón $\mathrm{Hm}^{3}$ /año, tanto para el uso público urbano de las principales juntas municipales, como para empresas agrícolas dedicadas al cultivo de hortalizas, aguacate $\mathrm{y}$, en fecha más reciente, uva de mesa e higo (El Informador, 2018), que no son comunes en la región.

\section{Presión antropogénica sobre el agua subterránea}

El número de concesiones y el volumen concesionado se utilizaron como indicadores de presión antropogénica sobre el agua subterránea. Las zonas con presión alta respecto a la cantidad de concesiones se encuentran en los acuíferos Colima y ATP, mientras que en los de Autlán, Tapalpa, Tecolotlán y Unión 
Figura 3. Número de títulos (a) y volumen concesionado (b) acumulados por acuífero, 1994-2015

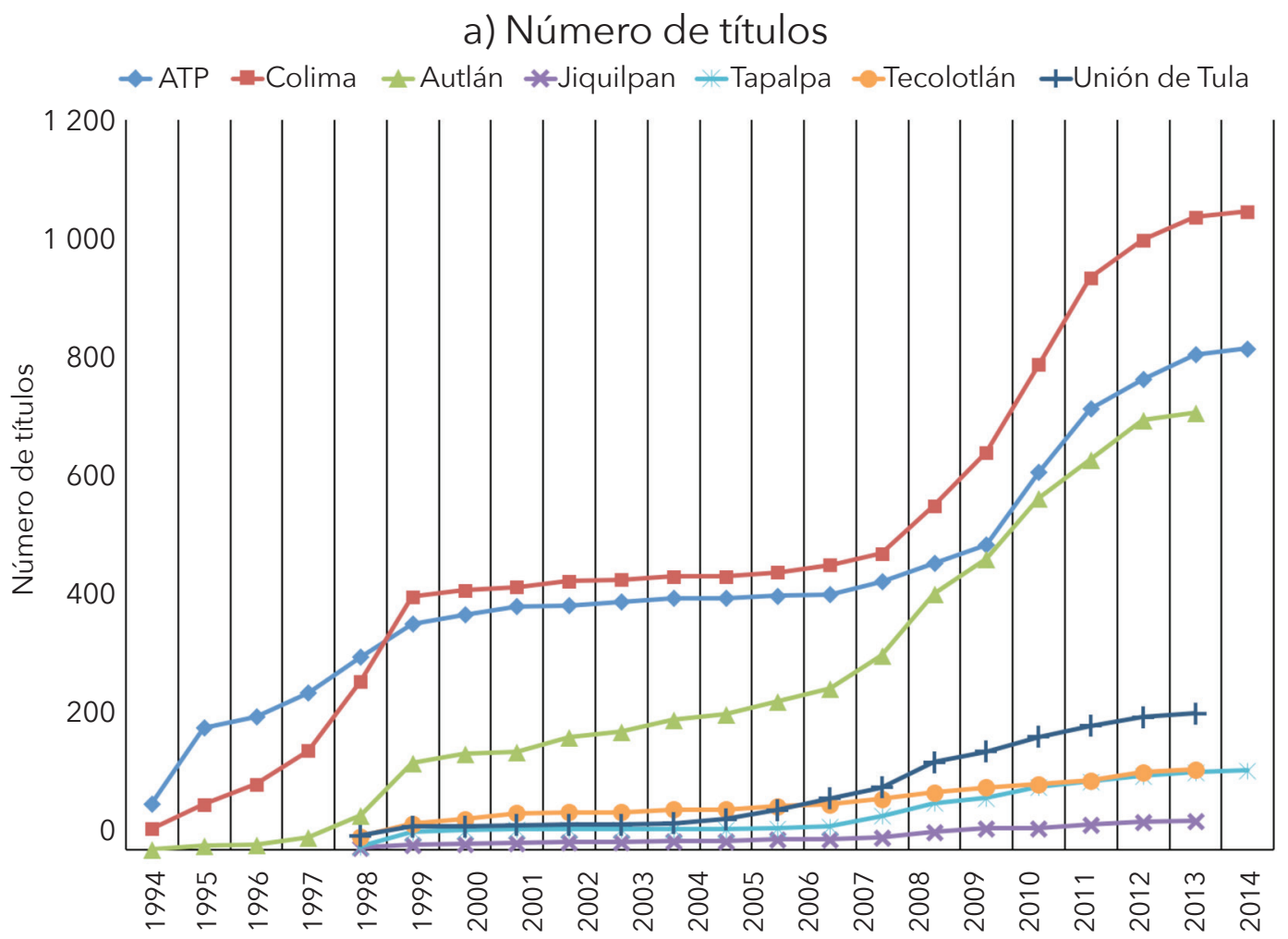

b) Volumen concesionado

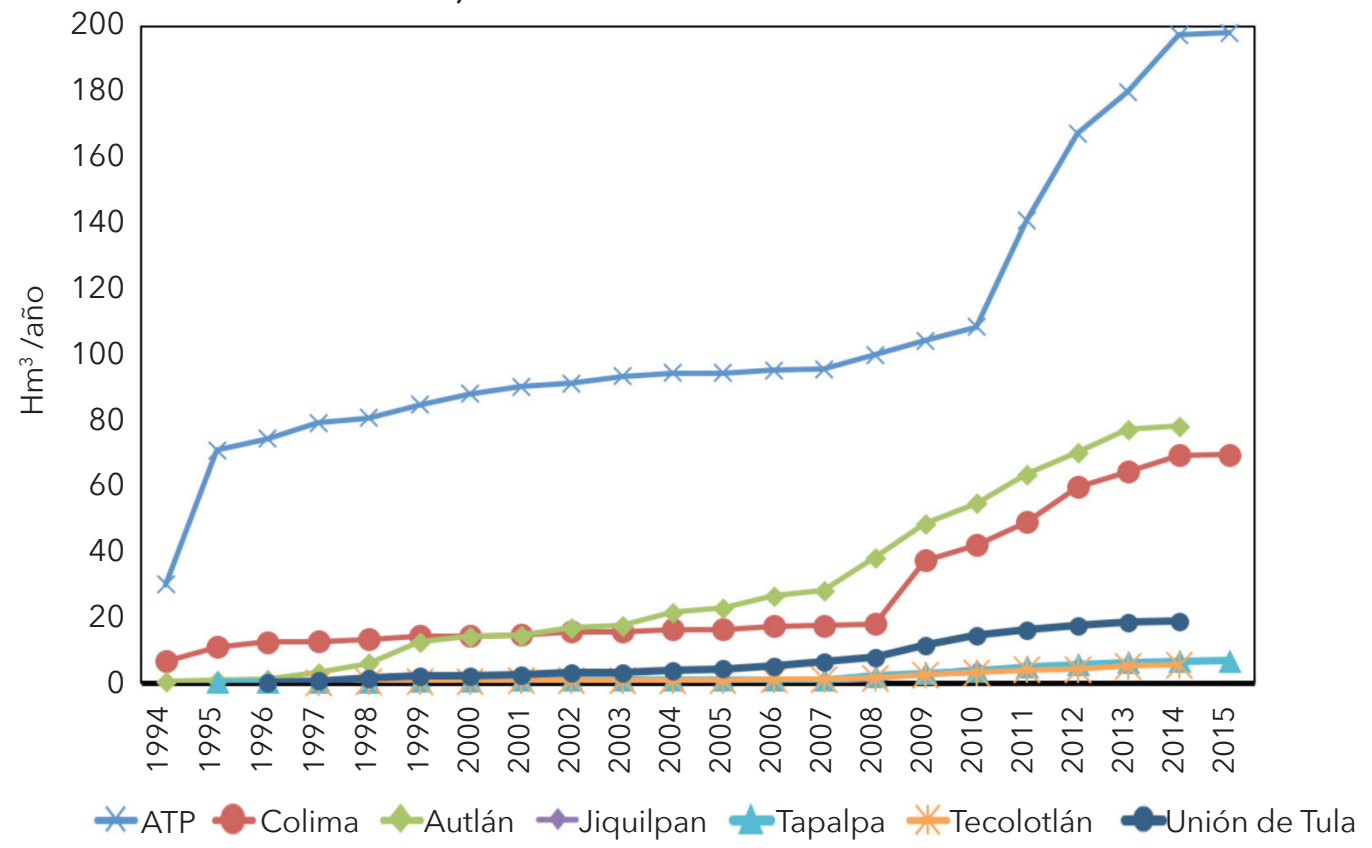

Fuente: elaboración propia, con información del REPDA (2015). 
Figura 4. Volumen concesionado por acuífero para uso agrícola (a) y público urbano (b),1994-2015

a) Uso agrícola

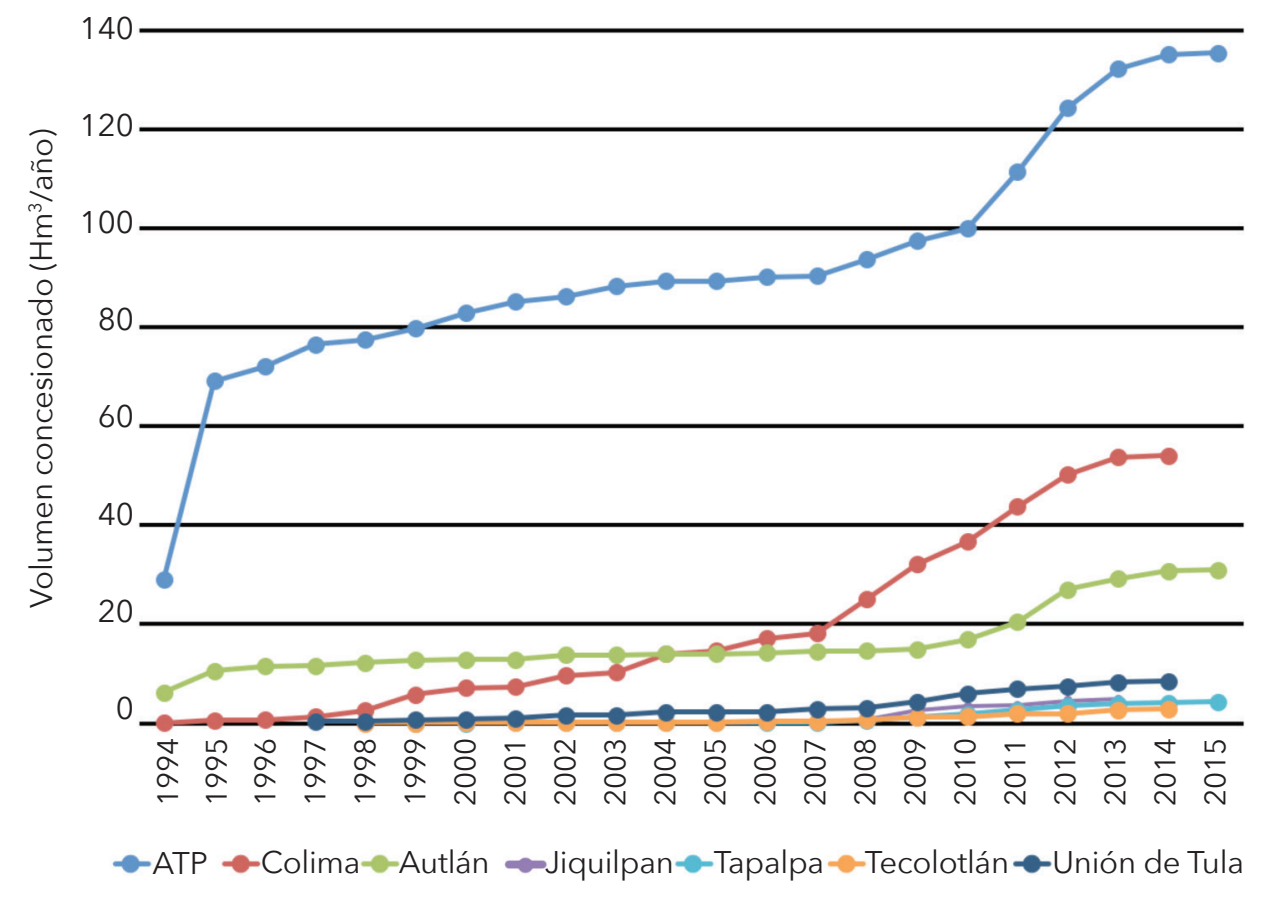

b) Uso público urbano

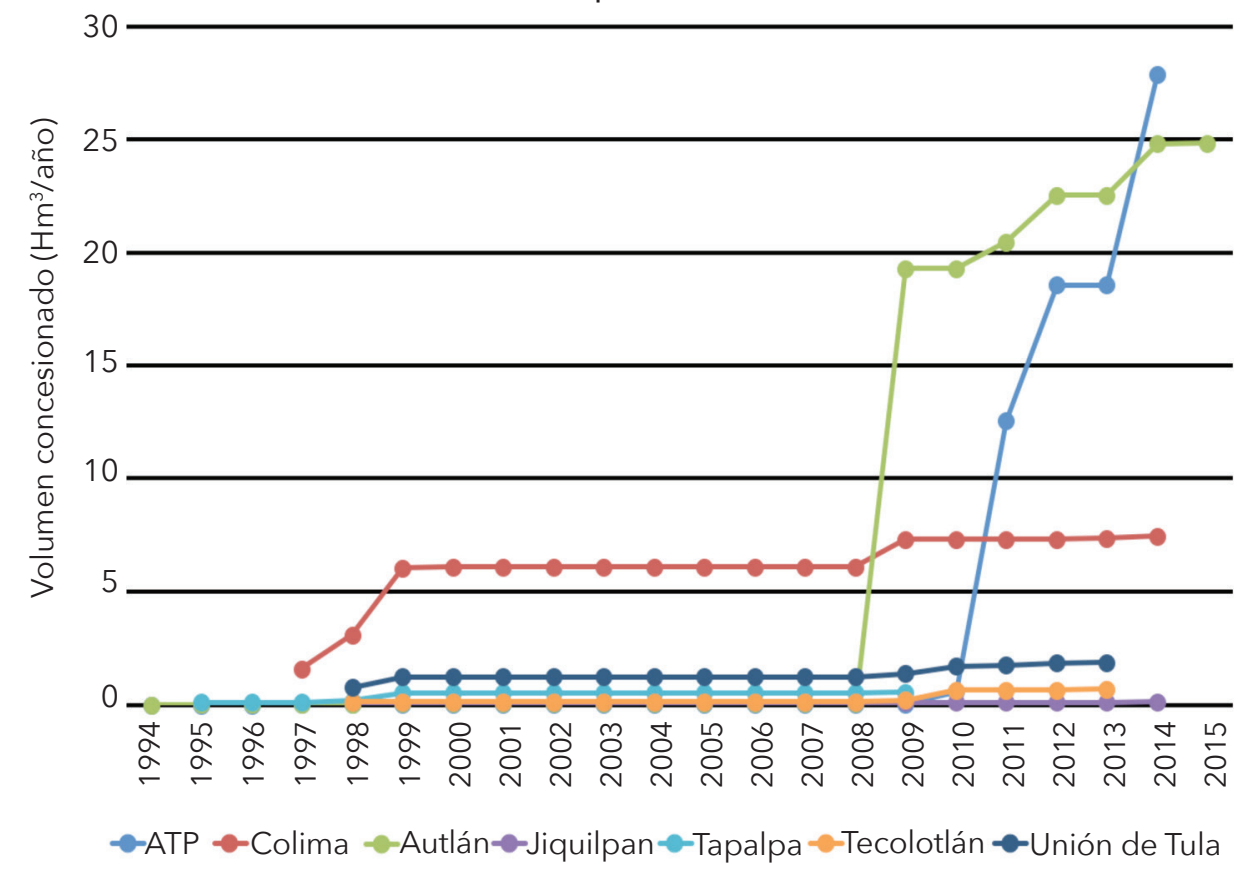

Fuente: elaboración propia, con información del REPDA (2015). 
de Tula presentan grandes zonas de presión media (véase figura 5a). En cuanto al volumen de extracción concesionado, la zona de presión alta solo se registró en el acuífero ATP, en tanto que las de presión media se ubicaron en los de ATP, Colima y Autlán, lo que coincide con algunas de las áreas urbanas principales (véase figura $5 b$ ).

El mapa de presión total combinada muestra las zonas de presión alta y media en los acuíferos ATP y Colima, que representan 24 y $30 \%$ de su superficie; en el de Autlán, $10 \%$ de la superficie presentó un grado de presión media y $90 \%$ una presión baja o nula (véase figura $5 c$ ). Estos mapas permiten identificar las zonas donde se prevé que surjan conflictos por el uso del agua entre los sectores, y que son estas zonas donde se presenten primero los daños por la explotación intensiva del agua. Sin embargo, estas son áreas de oportunidad para mejorar la gestión de agua subterránea, mediante el análisis del sobreconcesionamiento y el diseño de redes de monitoreo para medir los cambios en cuanto a su cantidad y calidad por la extracción intensiva, y compararlos con las zonas de menor presión.

Figura 5. Zonas de presión antropogénica de acuerdo con el número de concesiones (a), volumen concesionado (b) y presión total combinada (c)

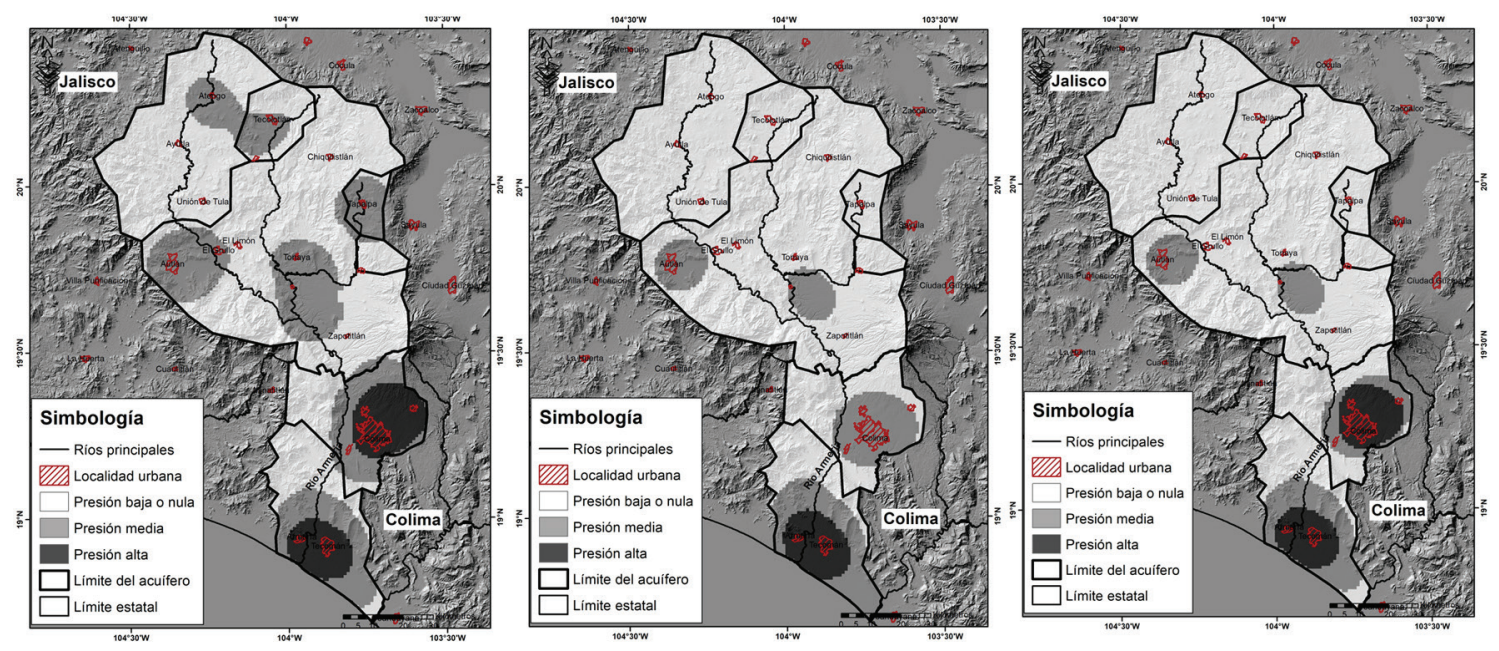

Fuente: elaboración propia, con información del REPDA (2015).

\section{Discusión}

\section{Asignación del agua}

Del volumen total concesionado en los acuíferos ( $382 \mathrm{Hm}^{3} /$ año), $70 \%$ está asignado a los de Colima y 30 a los de Jalisco. Los usos predominantes son el agrícola y el público urbano, y representan 63 y $17 \%$ del volumen total concesionado, y el destinado a la agricultura está por encima de la media nacional (36\%) y la mundial (43). El de uso público urbano está por debajo de la media nacional (22\%) y mun- 
dial (36) (CONAGUA, 2016a, p. 71; Döll et al., 2012, p. 143), aunque muestra un crecimiento rápido, pues se ha incrementado en 85 y $100 \%$, respectivamente, de 1994 a 2015. Esto se atribuye a las políticas de desarrollo del campo y a las tendencias de migración hacia las localidades urbanas (DOF, 2016, p. 26).

Las zonas con mayor presión antropogénica sobre el agua subterránea se ubicaron en la parte baja y salida de la cuenca, dentro de los acuíferos Colima y ATP, que coincide con las localidades urbanas con mayor densidad poblacional y más actividad económica, como la ciudad de Colima y la zona conurbada de Villa de Álvarez y Comala o el valle de Armería-Tecomán (DOF, 2016, p. 26). Es aquí donde se prevén mayores posibilidades de que surjan conflictos, pues los incrementos en el uso público urbano acrecentará la competencia con el agrícola, lo que podría limitar seriamente la producción de alimentos (Hanjra y Qureshi, 2010, p. 367).

Quizá el valle de Armería-Tecomán, en el acuífero ATP, sea un ejemplo claro de disputa por el agua entre las áreas urbanas y los distritos de riego, pues ahí se ubican dos de las unidades más grandes del distrito de riego 053, y algunas de las cabeceras municipales con mayor población en Colima. Hay problemas de abasto de agua potable y para riego, ya que el volumen de agua superficial que reciben, a través del río Armería, se reduce mucho por la extracción que se realiza algunos kilómetros más arriba, y el volumen de agua subterránea enfrenta una reducción por la explotación del acuífero para abastecer a Manzanillo (perteneciente al de Jalipa-Tapeixtles), a través de una batería de pozos y un acueducto de $50 \mathrm{~km}$ de longitud, que conduce $250 \mathrm{l} / \mathrm{s}$ (Mora, 2015). El ATP, al ser el único acuífero costero cuyas aguas descargan al mar, presenta mayor riesgo por la intrusión salina. La extracción intensiva del agua subterránea puede provocar el descenso de los niveles freáticos, y permitir el avance de la cuña salina de forma generalizada o localizada, y eliminar la posibilidad de seguir utilizando volúmenes importantes de agua subterránea (Pulido-Bosch, 2001, p. 119).

\section{Disponibilidad, manejo de la oferta y el papel del REPDA}

La función registral del REPDA ha oscilado entre la centralización y la descentralización, pues cuenta con un sistema de registro nacional y otro regional. Cada mes, en las oficinas regionales se recopila, captura y envía la información de los títulos registrados al sistema nacional para su incorporación. Este proceso ha generado un desfase y diferencias en el contenido de la información, reflejado en las discrepancias en el número de registros contenidos en las bases de datos del REPDA de la región hidrológica 16, enviado a los autores por la Gerencia del Registro Público de Derechos de Agua (5 177) y la Dirección del Registro Público de Derechos de Agua (3 173) del Organismo de Cuenca Lerma Santiago, lo cual genera incertidumbre sobre el número total de concesiones otorgadas, al observarse una diferencia de cerca de 2000 concesiones entre las bases de datos.

También es importante la calidad de la información contenida en la base de datos del REPDA, en cuyos registros se encontró que: a) 8\% de ellos presentó errores de localización, ubicaba la concesión fuera del límite del acuífero donde 
se solicitó, en otro estado, país o incluso en el mar; b) $11 \%$ no contaba con fecha de vencimiento de la concesión; c) $36 \%$ no tenía un medidor de consumo y d) $25 \%$ se encontraba vencido, en 2015. Esto contribuye a la falta de certeza en la información estadística del REPDA, que se traduce en mayor incertidumbre sobre el volumen real concesionado en los acuíferos, lo cual, a su vez, influye directamente en la estimación de la disponibilidad. Una gestión adecuada del agua por cuenca o acuífero requiere verificación y depuración de la información en la base de datos del REPDA, además de un sistema eficiente para su administración y manejo, que permita conocer los volúmenes concesionados y de disponibilidad en tiempo real.

Una de las ventajas principales de contar con un sistema de derechos concesionados, basado en la administración pública, es la posibilidad que tiene la agencia pública de elaborar la planificación del recurso hídrico, de acuerdo con principios de eficiencia, equidad y sostenibilidad (Méndez, 2008, p. 173). Sin embargo, en la práctica, las concesiones en estos acuíferos se otorgan sin planeación ni implementación de acciones que denoten una autoridad para controlar el uso del agua subterránea. Ejemplo de esto son los incrementos en el número de concesiones y volumen concesionados de 2007 a 2015. En los acuíferos Autlán y Jiquilpan, de 2013 a 2015, se concesionó más de 100\% de la disponibilidad anterior; provocando una situación de déficit en tan solo dos años. De tal manera que las concesiones son un mero registro, reconocimiento o legalización de los usos que ya se realizan y no se emplean como instrumento de gestión para limitar y moderar la extracción del agua subterránea (Pineda et al., 2014, p. 220). Sin embargo, en otras situaciones, las concesiones y su reglamentación se aplican de manera tajante para algunos usuarios, mientras que a otros se les exime, lo que genera conflictos entre la sociedad y la autoridad estatal. Esto se manifestó a partir de la promulgación de los Decretos de Reserva de Agua en diversas cuencas del país, publicados el 6 de junio de 2018, con los que se pretende extinguir las concesiones que no fueron renovadas a tiempo, y reconocer solo las vigentes. Es así que ahora hay 50000 concesiones "caducas" sobre todo en ejidos, comunidades y pueblos que no imaginaban que sus derechos de agua debían renovarse. Estos decretos permitirán que la CONAGUA garantice los volúmenes de agua que necesitan las empresas mineras, petroleras y privatizadoras de sistemas urbanos de agua, a costa de los derechos de agua de núcleos agrarios o comunidades indígenas y rurales (Fondo para la Comunicación y la Educación Ambiental, 2018).

La falta de gestión y control ha ocasionado el sobreconcesionamiento de los acuíferos provocando que se extraiga más agua de la que se recarga, como en el acuífero Autlán (CONAGUA, 2018, p. 56); situación utilizada por dicha dependencia para catalogar a los acuíferos como "sobreexplotados". Aunque este término carece de definición técnica y jurídica en las leyes mexicanas y su uso se considera inadecuado, pues implica conocer con exactitud los volúmenes de recarga y descarga del agua subterránea, que no son evaluados de manera precisa (Hatch, 2017, p. 158). El término puede ser útil para señalar algunos de los efectos negativos del desarrollo de los acuíferos, que son preocupantes para determinado grupo social, y sobre los cuales se deben aplicar acciones para co- 
rregirlos (Custodio, 2002, p. 260). Sin embargo, se recomienda usar el término desarrollo intensivo de aguas subterráneas para señalar cuando se extrae una gran fracción del recurso renovable interanual de los acuíferos que, en contrapartida, modifica considerablemente su régimen hidrológico, causa impactos ecológicos, políticos o socioeconómicos significativos, además de producir cambios importantes en la interacción río-acuífero (Llamas y Custodio, 2002, p. 224). Lo que sí se entiende es que la supuesta sobreexplotación proviene de prácticas administrativas ineficientes e insostenibles de aprovechamiento del agua (Carrillo et al., 2016, p. 8).

\section{Método del balance hídrico y la disponibilidad de agua subterránea}

La disponibilidad del agua subterránea es el criterio principal para otorgar las concesiones, sin embargo, no se analiza su variabilidad espacial y temporal dentro de los acuíferos; sino que solo se sigue la demanda de agua. Tampoco considera los aspectos sociales o culturales, ni las necesidades futuras de una región; muchas veces se privilegian las preocupaciones políticas o económicas sobre las necesidades sociales o ambientales. Lo que ha propiciado manifestaciones y protestas de inconformidad de la población en defensa de su territorio y recursos, desde Baja California hasta Quintana Roo (Reyes, 2017, p. 4).

El método balance hídrico no considera la heterogeneidad espacial de las propiedades hidráulicas del marco geológico, como la porosidad, el coeficiente de almacenamiento, la conductividad hidráulica y el espesor de la unidad acuífera o la presencia de límites hidráulicos naturales relacionadas con la disponibilidad de agua subterránea (Price, 2003, p. 150). El cálculo de la recarga mantiene un alto grado de incertidumbre; ya que no solo depende de la tasa de recarga, la cual es variable en el tiempo y en el espacio, sino que en ella también incide el cambio de uso de suelo y la extensión de la superficie sobre la que se estima, la cual es poco clara, en especial cuando hay flujos horizontales y verticales provenientes de otros acuíferos (Carrillo-Rivera, 2000, p. 519; Custodio, 2002, p. 258).

Puesto que cada vez hay menos presupuesto e infraestructura para medir los parámetros ambientales (evapotranspiración, precipitación o escurrimiento) y el consumo, el valor publicado de los parámetros para calcular la disponibilidad solo es aproximado (Carrillo-Rivera et al., 2016, p. 5). Esto se ve reflejado en el valor de la recarga utilizado en el cálculo de la disponibilidad, el cual permaneció constante de 2003 a 2015 (véase figura 5), y en algunos casos se deriva de estudios realizados hace más de 28 años (CONAGUA, 2002, p. 15). Considerar que las tasas de recarga de los acuíferos son constantes en el tiempo, sin tomar en cuenta las oscilaciones globales en el clima y la precipitación es un paradigma que puede llevar a una sobreestimación o subestimación del volumen de agua, pues dichas tasas son sensibles a esas condiciones (Vaccaro, 1992; Hiscock, 2006). Así parece poco probable que el volumen de recarga no haya variado a lo largo del tiempo, si se toman en cuenta las variaciones climáticas de México a 
partir de la década de 1980, como la ocurrencia de los fenómenos de La Niña y El Niño (Magaña, Pérez y Conde, 1998), lo que pone en duda los valores utilizados.

Otro aspecto importante en el cálculo de la disponibilidad es la ausencia de un volumen de descarga natural comprometida, como en los acuíferos Autlán y Jiquilpan, lo cual refleja la falta de información y una metodología clara para estimar el caudal base de descarga de los acuíferos. Si no se considera este caudal mínimo de descarga de un acuífero para proteger las condiciones ambientales y el equilibrio ecológico de los sistemas dependientes del agua subterránea como ríos y humedales, no se puede garantizar que la extracción sea sustentable, es decir, que no se extraiga más agua de los umbrales necesarios para que los ecosistemas se mantengan sanos, y se conserve el ciclo hidrológico de la relación agua superficial-agua subterránea (Carabias, Landa, Collado y Martínez, 2005, p. 197; Llanos y Fernández, 2017. p. 34), especialmente durante el periodo de estiaje, cuando es más intensa la competencia entre los agricultores y los ecosistemas naturales.

Otro aspecto de gran relevancia en la gestión del agua subterránea es la conceptualización y delimitación de los acuíferos. Los límites laterales y verticales se definen convencionalmente para fines de evaluación y administración del agua subterránea. Estos acuíferos administrativos son áreas imaginarias, que están fuera de sus límites y naturaleza geológica, hidráulica, de vegetación y suelo, de la trayectoria, dimensión, velocidad y jerarquía de los sistemas de flujo (Carrillo-Rivera et al., 2016, p. 7). En la LAN, la delimitación actual de los acuíferos está concebida como una especie de receptáculo semejante a una cubeta que contiene agua sin movimiento aparente (lista para ser aprovechada), y que se encuentra acomodada en planos horizontales, uno detrás de otro en todo el territorio nacional (Hatch, 2017, p. 158). Esta visión no contribuye a que se analice la dinámica del agua subterránea desde un panorama completo en el sistema; sino tan solo en porciones imaginarias pequeñas, ocultando el hecho de que el agua subterránea fluye de un acuífero a otro, que cada uno cuenta con zonas de recarga y descarga, y que la calidad fisicoquímica del agua varía en relación con los componentes ambientales (Peñuela et al., 2016, p. 151).

Al sobreponer las concesiones con el mapa geológico de la cuenca (Servicio Geológico Mexicano, 2016), se observó que 51\% del volumen concesionado proviene de los depósitos aluviales del holoceno y $25 \%$ de la unidad lahar-piroclásto, que conforman la base de los volcanes Nevado de Colima y el Volcán de Fuego. Aunque es bien sabido que el agua no reconoce límites políticos, esta unidad lahar-piroclásto está dividida en cuatro acuíferos, dos en Jalisco y dos en Colima, donde el límite entre las dos entidades sigue la división estatal.

De estos acuíferos, Autlán y Ciudad Guzmán, en Jalisco, y Alzada-Tepames, en Colima, presentan un déficit de $-6.0 \mathrm{Hm}^{3} /$ año, $-26.9 \mathrm{Hm}^{3} /$ año y -0.1 $\mathrm{Hm}^{3} /$ año respectivamente; mientras que el acuífero Colima aún mantiene un disponibilidad de $1.8 \mathrm{Hm}^{3}$ /año (DOF, 2018, pp. 13-14). Situación que obliga a suspender el otorgamiento de concesiones en tres cuartas partes de la unidad hidrogeológica, en tanto que en otra aún es posible incrementar la extracción. El hecho de que una unidad hidrogeológica homogénea, como la de lahar-piroclásto, se divida en cuatro acuíferos ya es un antecedente para 
conflictos futuros, sobre todo cuando hay más de una institución que gestiona el agua con bases de datos distintas, lo que complica el proceso de gestión y la toma de decisiones (Carrillo-Rivera et al., 2016, p. 7).

De acuerdo con la LAN, los decretos para el establecimiento de zonas de veda se pueden expedir en casos de sobreexplotación, sequía o escasez extrema, en situaciones motivadas por contaminación o aprovechamiento de las aguas nacionales superficiales o del subsuelo. Si se toma el criterio de sobreexplotación en los términos de la CONAGUA, en Autlán sería necesario establecer una zona de veda para restringir la autorización de concesiones adicionales en toda la superficie, aunque los efectos negativos de la extracción intensiva se espera se presenten en $10 \%$ de la superficie del acuífero. El conocimiento de los sistemas de flujo y su funcionamiento permitiría estimar la capacidad de respuesta a la extracción, y con ello ajustar y actualizar las concesiones y asignaciones a la oferta real de agua subterránea, a los impactos ambientales involucrados "por controlar"; además de actualizar y puntualizar los decretos de veda, reserva y zonas reglamentadas (Carmona-Lara, Carrillo-Rivera, Hatch-Kuri, Huízar-Álvarez y Ortega-Guerrero, 2017, p. 29).

La teoría de los sistemas de flujo permite representar al ambiente hidrogeológico bajo un modelo conceptual, que integra parámetros geológicos, hidrológicos, edáficos, de vegetación y geomorfológicos, que determinan el régimen de flujo de agua subterránea, el cual ocasiona manifestaciones contrastantes en superficie entre las zonas de recarga y descarga (Tóth, 2009, p. 93). La definición de estas zonas, mediante indicadores superficiales, junto con el análisis de la calidad química del agua, contenido isotópico, así como las propiedades y cargas hidráulicas para definir las trayectorias de los flujos involucrados permiten conocer el funcionamiento del agua subterránea (Peñuela-Arévalo y Carrillo-Rivera, 2013, p. 31). Este conocimiento debe reflejarse en políticas públicas para lograr la sustentabilidad del agua subterránea (Carmona et al., 2017, p. 7).

\section{Marco normativo y sus efectos en la extracción de agua subterránea}

Existen grandes contradicciones entre las prácticas que se fomentan por la reglamentación de las concesiones y la necesidad de conservar el agua, pues la CONAGUA está subordinada a lo que dice la ley, la cual no establece restricciones por temporalidad y variabilidad espacial de la disponibilidad o las tasas máximas tolerables de extracción de un acuífero. La seguridad jurídica que se menciona en el otorgamiento de las concesiones puede ser efectiva frente a otros demandantes, pero no cuando se trata de limitaciones en la disponibilidad natural del recurso (Pineda et al., 2014, p. 202). Estos aspectos favorecen a los usuarios y no a la autoridad para el control del agua subterránea.

La ley también establece que los concesionarios deben limitar sus extracciones al volumen autorizado, contar con un medidor para la extracción y hacer un uso eficiente del agua. Sin embargo, no se establecen disposiciones para que 
los usuarios ahorren o conserven las fuentes de suministro tratando de utilizar volúmenes menores a los que les fueron concesionados (Pineda et al., 2014, p. 202). Este principio de razonabilidad y uso eficiente del agua subterránea no es un criterio suficientemente claro para los usuarios. En el sistema de producción actual, basado en maximizar el valor presente neto de los beneficios que genera la extracción en el tiempo, se ignora la dinámica natural de los sistemas de flujo del agua subterránea, que puede provocar el descenso continuo y prolongado de los niveles freáticos. Este abatimiento puede perjudicar la sustentabilidad hídrica de una región, y reducir el acceso al agua subterránea, lo que ocasionaría una desigualdad en el acceso y aumentaría la posibilidad de conflicto entre los usuarios. Así, ellos no advierten los costos de oportunidad por usar menos agua; pues el recurso que no extraigan hoy, no necesariamente estará disponible para el futuro, y puede ser utilizado por otros usuarios, en lugar de contar con un beneficio por el ahorro logrado.

Es necesario incorporar en la ley la expresión de "rendimiento sostenible y sustentable", entendida como la cantidad anual máxima de agua subterránea que se puede extraer de un acuífero, sin causar efectos adversos en un periodo base que represente condiciones a largo plazo, e incluya cualquier excedente temporal. Además del concepto de "daño al ambiente", para salvaguardar su cantidad, calidad y la preservación de los acuíferos de los efectos adversos generados por la extracción fuera de los límites señalados en las autorizaciones, permisos y concesiones (Carmona et al., 2017, pp. 26 y 27).

\section{Conclusiones}

Una de las ventajas principales de contar con un sistema de derechos concesionados, basado en la administración pública, es la posibilidad que tiene dicha agencia de elaborar la planificación y gestión del agua subterránea. Sin embargo, el otorgamiento de concesiones en estos acuíferos se efectúa sin planeación de la oferta y la demanda. Las concesiones de agua subterránea no se están utilizando como instrumento de gestión para limitar y controlar su extracción, lo que ha provocado el sobreconcesionamiento de los acuíferos de la cuenca del río Ayuquila-Armería. A esto debe sumarse la escasa capacidad para la integración, verificación y manejo de la información de las concesiones, lo cual ha propiciado errores y rezagos que impiden contar con datos verídicos y tiempo real sobre el volumen de extracción concesionado. Por lo cual, es necesario que el REPDA cuente con un sistema eficiente para incorporar y procesar la información, que permita conocer la demanda y la disponibilidad en tiempo real.

El número de concesiones y volumen concesionado se pueden utilizar como indicadores de presión antropogénica sobre el agua subterránea, y los modelos de densidad permiten identificar las áreas donde se prevé que se acentúen los efectos de la extracción intensiva y la mayor posibilidad de que surjan conflictos entre los usuarios. Estas son también las áreas de oportunidad para comenzar a diseñar estrategias de monitoreo y en las que se deberán aplicar medidas efectivas de control y protección del agua subterránea. 
Las concesiones se otorgan con base en métodos obsoletos, derivados de la hidrología superficial, sin información precisa de las variables involucradas y utilizando estimaciones aproximadas de los procesos que intervienen en la disponibilidad del agua subterránea en los acuíferos, sobre superficies ficticias con límites político-administrativos fuera de los del funcionamiento de los sistemas de flujo. De tal manera que es necesario un mayor esfuerzo e inversión de recursos financieros para el diagnóstico y monitoreo del consumo (establecimiento de medidores), la recarga y descarga natural de los acuíferos, así como para el monitoreo de la cantidad y calidad del agua subterránea. Además de invertir en la capacitación de especialistas y el desarrollo de proyectos de investigación con enfoques nuevos, como la teoría de los sistemas de flujo, que contribuyan a incrementar el conocimiento sobre los sistemas de agua subterránea y su administración en el país. En síntesis, es necesario un cambio de visión en la gestión, la legislación y las políticas públicas que ayude a establecer un marco regulatorio específico sobre el agua subterránea, como la propuesta de ley elaborada por Carmona et al., en 2017, para mejorar la gestión sobre el agua subterránea.

\section{Referencias}

Carabias, J. (2017). Agua para principiantes. Nexos, 475, 21-27. Recuperado de: https: / /www. nexos.com.mx/?p=32794

Carabias, J., Landa, R., Collado, J., y Martínez, P. (2005). Agua, medio ambiente y sociedad. Hacia la gestión integral de los recursos hídricos en México. Ciudad de México: Universidad Nacional Autónoma de México (UNAM), El Colegio de México, Fundación Gonzalo Río Arronte.

Carmona-Lara, C., Carrillo-Rivera, J. J., Hatch-Kuri, G., Huízar-Álvarez, R., y Ortega-Guerrero, M. A. (2017). Ley del Agua Subterránea: una propuesta. Publicaciones del Instituto de Geografía, UNAM. Recuperado de: http://www. publicaciones.igg.unam.mx/index.php/ig/catalog/book/102

Carrillo-Rivera, J. (2000). Application of the groundwater-balance equation to indicate interbasin and vertical flow in two semi-arid drainage basins, Mexico. Hydrogeology Journal, 8(5), 503-520. doi: 10.1007/s100400000093

Carrillo-Rivera, J. J., Peñuela-Arévalo, L.A., Huízar-Álvarez, R., Cardona-Benavides, A., Ortega-Guerrero, M. A., Vallejo-Barra, J., y Hatch-Kuri, G. (2016). Conflictos por el agua subterránea. En J. O. Moncada Maya y A. López López (coords), Geografía de México: una reflexión espacial contemporánea (pp. 1-16). Ciudad de México: Instituto de Geografía, UNAM.

Comisión Nacional del Agua (CONAGUA). (2002). Determinación de la disponibilidad de agua en el acuífero Colima, estado de Colima (pp. 5-7). Ciudad de México: Gerencia de Aguas Subterráneas, CONAGUA.

Comisión Nacional del Agua (CONAGUA). (2008). Determinación de la disponibilidad de agua en el acuífero Tapalpa, estado de Jalisco (p. 4). Ciudad de México: Gerencia de Aguas Subterráneas, CONAGUA.

Comisión Nacional del Agua (CONAGUA). (2012). Memoria documental: Registro Público de Derechos de Agua (p. 1-34). Ciudad de México: Secretaría de Medio Ambiente y Recursos Naturales. 
Comisión Nacional del Agua (CONAGUA). (2015). Disponibilidad por acuíferos. Ciudad de México. CONAGUA. Recuperado de: http://www.gob.mx/Conagua/acciones-y-programas/jalisco-74861

Comisión Nacional del Agua (CONAGUA). (2018). Estadísticas del agua en México (p. 72-99), edición 2018. Ciudad de México: CONAGUA.

Custodio, E. (2002). Aquifer overexploitation: What does it mean? Hydrogeology Journal, 10(2), 254-277.

Díaz-Caravantes, R. E., Bravo-Peña, L. C., Alatorre-Cejudo, L. C., y Sánchez-Flores, E. (2013). Presión antropogénica sobre el agua subterránea en México: una aproximación geográfica. Investigaciones Geográficas, 82, 93-103. Boletín del Instituto de Geografía, UNAM.

Diario Oficial de la Federación (DOF). (2003). Acuerdo por el que se dan a conocer los límites de 188 acuíferos de los Estados Unidos Mexicanos, los resultados de los estudios realizados para determinar su disponibilidad media anual de agua y sus planos de localización (pp. 1-112). Ciudad de México: Secretaría de Gobernación México.

Diario Oficial de la Federación (DOF). (2009). Acuerdo por el que se da a conocer la ubicación geográfica de 371 acuíferos del territorio nacional, se actualiza la disponibilidad media anual de agua subterránea de 282 acuíferos y se modifica, para mejorar su precisión la descripción geográfica de 202 acuíferos (pp. 1-402). Ciudad de México: Secretaría de Gobernación.

Diario Oficial de la Federación (DOF). (2013). Acuerdo por el que se actualiza la disponibilidad media anual de agua subterránea de los 653 acuíferos de los Estados Unidos Mexicanos, mismos que forman parte de las regiones hidrológico-administrativas que se indican (pp. 1-100). Ciudad de México. Secretaría de Gobernación.

Diario Oficial de la Federación (DOF). (2015a). Acuerdo por el que se actualiza la disponibilidad media anual de agua subterránea de los 653 acuíferos de los Estados Unidos Mexicanos, mismos que forman parte de las regiones hidrológicas administrativas que se indican (pp. 1-56). Ciudad de México: Secretaría de Gobernación.

Diario Oficial de la Federación (DOF). (2015b). Norma Oficial Mexicana NOM011-CONAGUA-2015, Conservación del recurso agua que establece las especificaciones y el método para determinar la disponibilidad media anual de las aguas nacionales (pp. 1-16). Ciudad de México: Secretaría de Gobernación.

Diario Oficial de la Federación (DOF). (2016a). Ley de Aguas Nacionales, última reforma publicada el 24 de marzo de 2016. Ciudad de México. Recuperado de http: / / www.diputados.gob.mx/LeyesBiblio/pdf/16_240316.pdf

Diario Oficial de la Federación (DOF). (2016b). Acuerdo por el que se da a conocer el resultado de los estudios técnicos de aguas nacionales superficiales de la subregión hidrológica Río Arenería de la región hidrológica número 16 Armería-Coahuayana (pp. 1-26). Ciudad de México. Secretaría de Gobernación.

Diario Oficial de la Federación (DOF). (2018). Acuerdo por el que se actualiza la disponibilidad media anual de agua subterránea de los 653 acuíferos de los Estados Unidos Mexicanos, mismos que forman parte de las Regiones hidroló- 
gico-administrativas que se indican (pp. 1-2018). Ciudad de México: Secretaría de Gobernación.

Döll, P., Hoffmann-Dobrev, H., Portmann, F., Siebert, S., Eicker, A., Rodell, M., Strassberg, G., y Scanlon, B. (2012). Impact of water withdrawals from groundwater and surface water on continental water storage variations. Journal of Geodynamics, 59-60, 143-156. doi:10.1016/j.jog.2011.05.001

Environmental Systems Research Institute (ESRI). (2014). ArcGIS Desktop Help 10.2, Spatial Autocorrelation (Global Moran's I). Recuperado de: http://resources.arcgis.com/en/help/main/10.2/index.html

El Informador. (1 de diciembre de 2018). Crece en Jalisco el valor de la producción agropecuaria. El sexenio de Aristóteles Sandoval cierra con cifras récord en el periodo 2012-2018. Recuperado de https://www.informador.mx/Crece-en-Jalisco-el-valor-de-la-produccion-agropecuaria-(201812010003.html

Fondo para la Comunicación y la Educación Ambiental (FCEA). (18 de junio de 2018). Análisis del decreto de reservas de agua para uso público urbano, ambiental y de generación de energía eléctrica. Agua.org. $\mathrm{mx}$. Recuperado de https://agua.org.mx/biblioteca/analisis-del-decreto-de-reservas-de-agua-para-uso-publico-urbano-ambiental-y-de-generacion-de-energia-electrica/

Foster, S., y Cherlet, J. (2014). Why does land-groundwater interaction matter. En Technical Committee (ed.), The links between land use and groundwater (pp. 4-9). Estocolmo: Global Water Partnership.

Graf-Montero, S., Martínez-Rivera, L. M., Santana-Castellón, E., e Î́niguez-Dávalos, L. I. (2002). Región hidrológica prioritaria río Purificación-Manantlán. En L. Arriaga-Cabrera, V. Aguilar Sierra y J. Alcocer Durad (coords.), Aguas continentales y diversidad biológica de México (pp. 74-75). Ciudad de México: Comisión Nacional para el Conocimiento y Uso de la Biodiversidad.

Gleeson, T., Befus, K. M., Jasechko, S., Luijendijk, E., y Cardenas, M. B. (2016). The global volume and distribution of modern groundwater. Nature Geoscience, 9(2), 1-6. doi: 10.1038/NGEO2590

Hanjra, M. A., y Qureshi, M. E. (2010). Global water crisis and future food security in an era of climate change. Food Policy, 35(5), 365-377. doi:10.1016/j. foodpol.2010.05.006

Gutiérrez, O. C., y Ortiz, F. G. (2017). Proyectos de recarga MAR en el acuífero principal de la región lagunera, México. En O. Escolero, C. Gutiérrez y E. Mendoza (eds.), Manejo de la recarga de acuífero: un enfoque hacia Latinoamérica (pp. 139-158). Jiutepec: Instituto Mexicano de Tecnología del Agua.

Hatch Kuri, G. (2017). Agua subterránea en México: retos y pendientes para la transformación de su gestión. En Ch. Denzin, F. Taboada y R. Pacheco-Vega (eds.), El estado del agua en México. Actores, sectores y paradigmas para una transformación social-ecológica (pp. 149-170). Ciudad de México: Fundación Friedrich Ebert Stiftung-Proyecto Regional Transformación Social-Ecológica.

Hatch Kuri, G., y Carrillo Rivera J. J. (2017). ¿Qué hacer con el agua subterránea? Nexos, 475,1. Recuperado de https://www.nexos.com.mx/?p=32765

Hergt, T., Larragoitia, J. C., Benavides, A. C., y Carrillo-Rivera, J. J. (2009). Análisis multivariado en la definición de sistemas de flujo de agua subterránea en San Luis Potosí, México. Tecnología y Ciencias del Agua, 24(4), 37-54. 
Hiscock, K. (2006). Climate change and groundwater resources. En K. Hiscock (ed). Hydrogeology: Principles and practice (pp. 302-316). Oxford: Blackwell Science.

Huizar-Alvarez, R., Ouysse, S., Espinoza-Jaramillo, M. M., Carrillo-Rivera, J. J., y Mendoza- Archundia, E. (2016). The effects of water use on Tothian flow systems in the Mexico City conurbation determined from the geochemical and isotopic characteristics of groundwater. Environmental Earth Sciences, 75(13), 1-17. doi: 10.1007/s12665-016-5843-7

Instituto Nacional de Estadística y Geografía (INEGI). (2010). XIII Censo de Población y Vivienda 2010. INEGI, Aguascalientes, México.

Instituto Nacional de Estadística y Geografía (INEGI). (2016). Marco geoestadístico, versión 4.3 (Censo de Población y Vivienda 2010). Aguascalientes, México.

Jardel, P. E. J. (coord.). (1992). Estrategias para la conservación de la Reserva de la Biosfera Sierra de Manantlán: propuesta para el Programa de Manejo Integral. Guadalajara: Universidad de Guadalajara.

Llamas, M. R., y Custodio, E. (2002). Acuíferos explotados intensivamente: conceptos principales, hechos relevantes y algunas sugerencias. Boletín Geológico y Minero de España, 113(3), 223-228.

Llanos, M., y Fernández, H. (comps.). (2017). Análisis y propuestas para la conservación de la biodiversidad en México 1995-2017. Ciudad de México: Biodiversidad2016.

Magaña, R. V., Pérez, J. L., y Conde, C. (1998). El fenómeno de El Niño y la oscilación del sur. Sus impactos en México. Ciencias, 51, 14-18.

Martínez-Rivera, L. M., Graf-Montero, S., Santana-Castellón, E., y García Ruvalcaba, S. (2005). Gestión y manejo del agua en la cuneca del río Ayuquila. Ponencia presentada en el Primer Congreso Internacional de Casos Exitosos de Desarrollo Sostenible en el Trópico. Boca del Río, México.

Méndez Sayago, J. A. (2008). Sistemas de derechos de agua: un análisis comparativo de la eficiencia económica en la asignación del recurso. Revista Sociedad y Economía, 14, 155-181. Recuperado de http://www.redalyc.org/ articulo. oa?id=99616725007

Mora, L. A., de la. (21 de octubre de 2015). Problemática de abasto de agua en Armería es un reto: Eusebio Mesina. Contexto Colima. Recuperado de: http: / / contextocolima.com/index.php/home/nota/2359

Organización de las Naciones Unidas para la Alimentación y la Agricultura. (2016). Global diagnostic on groundwater governance (pp. 3-15). Roma. Organización de las Naciones Unidas para la Alimentación y la Agricultura.

Ortega-Guerrero, M. A. (2009). Presencia, distribución, hidrogeoquímica y origen de arsénico, fluoruro y otros elementos traza disueltos en agua subterránea, a escala de cuenca hidrológica tributaria de Lerma-Chapala, México. Revista Mexicana de Ciencias Geológicas, 26(1), 143-161. Recuperado de http://www.scielo.org.mx/scielo.php?script=sci_arttext\&pi$\mathrm{d}=\mathrm{S} 1026-87742009000100012 \& \operatorname{lng}=e s \& t \operatorname{lng}=e s$

Ortega, G. J., y Velasco, M. A. (2012). La problemática del agua en el valle de México, antecedentes históricos. En Modelo de Marco Institucional para la Gestión de los Recursos Hídricos en el Valle de México (pp.13-18). Primer 
informe. Banco Interamericano de Desarrollo. Recuperado de http://www. agua.unam.mx/sacmex/assets/docs/IDBDOCS_GRH_ValleMexico.pdf

Peñuela Arévalo, L. A., y Carrillo Rivera, J. J. (2013). Definición de zonas de recarga y descarga de agua subterránea a partir de indicadores superficiales: centro-sur de la mesa central, México. Investigaciones Geográficas, (81), 1832.

Peñuela, L. A., García Rubio, G., y Carrillo Rivera, J. J. (2016). Importancia del agua subterránea en la conservación de los ecosistemas. En Biodiversidad en el Distrito Federal: estudio de Estado. Sección Medio Físico (pp. 145-164). México: Gobierno del Distrito Federal, Dirección General de Zoológicos y Vida Silvestre y Comisión Nacional para el Conocimiento y Uso de la Biodiversidad.

Pineda-Pablos, N., Moreno-Vásquez, J. L., Salazar-Adams, A., y Lutz-Ley, A. N. (2014). Derechos de agua y gestión por cuencas en México. El caso del río Sonora. Espiral Estudios sobre Estado y Sociedad, XXI(61), 191-225.

Price, M. (2003). Agua subterránea. México: Editorial Limusa.

Pulido-Bosch, A. (2001). Sobreexplotación de acuíferos y desarrollo sostenible. Problemática de la gestión del agua en regiones semiáridas. En A. Pulido Bosch, P. A. Pulido Leboeuf y J. M. Calaforra Chordi (coords.), Problemática de la gestión del agua en regiones semiáridas (pp. 115-132). Almería: Instituto de Estudios Almerienses.

Registro Público de Derechos de Agua (REPDA). 2015. Base de datos. Comisión Nacional del Agua, Subdirección General de Administración del Agua. Recuperado a través del Sistema INFOMEX.

Reyes, J. (8 de agosto de 2017). La crisis del agua, detonante de conflicto social. Contralínea, 1-13. Recuperado de https://www.contralinea.com.mx/archivo-revista/2017/08/08/la-crisis-del-agua-detonante-de-conflicto-social/

Rodríguez-Aguilar, B. A. (2017). Análisis de plaguicidas como fuente de contaminación de agua superficial dentro de la cuenca del río Ayuquila-Armería (tesis de maestría), Universidad de Guadalajara, Autlán de Navarro.

Servicio Geológico Mexicano. (2016). Continuo nacional de geología de la república mexicana. Escala 1:1250 000. México.

Tóth, J. (2009). Gravitational systems of groundwater flow: Theory, evaluation, utilization. Cambridge University Press. doi:10.1017/CB09780511576546

United Nations Educational, Scientific and Cultural Organization (UNESCO). (2012). Knowledge base (vol. 2). The United Nations World Water Development Report 4 (pp.77-85). París: United Nations Educational, Scientific and Cultural Organization.

Vaccaro, J. (1992). Sensitivity of groundwater recharge estimates to climate variability and change, Columbia Plateu, Washington. Journal of Geophysical Research, 97, 2821-2833. 